Professora no Departamento de Economia e Relações Internacionais, nos Programas de Pós-Graduação em Administração Pública - PPGAP (acadêmico), Gestão de Organizações Públicas - PPGOP (profissional) e Economia e Desenvolvimento PPGE\&D da Universidade Federal de Santa Maria (UFSM). Doutora (2013) e Mestre (2009) em Economia Aplicada pela Universidade de São Paulo- ESALQ/ USP. Possui graduação em Ciências Econômicas pela Universidade Federal de Santa Maria (2007).

\section{EFICIÊNCIA DOS GASTOS PÚBLICOS COM EDUCAÇÃO NOS MUNICÍPIOS DO RIO GRANDE DO SUL EM 2015}

\author{
EFFICIENCY OF PUBLIC EXPENDITURE ON EDUCATION \\ IN THE CITIES OF RIO GRANDE DO SUL - 2015
}

Douglas Chacon ${ }^{1}$ Kalinca Leia Becker ${ }^{2}$

RESUMo: A educação é um direito social e dever do Estado, sendo que um aumento nos gastos públicos com qualidade nessa área resulta em um maior crescimento econômico, visto que um maior investimento neste setor gera uma melhoria significativa da qualidade de vida dos indivíduos. As políticas sociais, quando analisadas pela ótica do Estado de Bem Estar Social, devem ser tratadas como um investimento social, e não como um custo, uma vez que são fatores inseridos no desenvolvimento humano. Para que os gastos públicos com educação sejam eficazes, é necessário que o aumento dos gastos seja acompanhado de maior critério e qualidade, sendo que o desempenho e o desenvolvimento dos alunos devem ser alcançados através desta eficiência educacional. Com isso, o estudo tem como objetivo analisar os gastos com educação no Rio Grande do Sul em 2015, verificando se os recursos estão sendo alocados de forma eficiente. Os resultados obtidos demonstram que quase metade dos municípios analisados se mostraram eficientes na alocação dos gastos na função educação.

palavras-chaves: Gastos Públicos. Educação. Eficiência. Desenvolvimento Socioeconômico.

ABSTRACT: Education is a social right and a duty of the State, and an increase in quality public spending in this area results in greater economic growth, since greater investment in this sector generates a significant improvement in the quality of life of individuals. Social policies, when analyzed from the point of view of the Welfare State, should be treated as a social investment, not as a cost, since they are factors that are part of human development. In order for public education expenditures to be effective, increased spending must be accompanied by greater criteria and quality, and the performance and development of students must be achieved through this educational efficiency. Therefore, the study aims to analyze spending on education in Rio Grande do Sul in 2015, verifying that resources are being allocated efficiently. The results show that almost half of the municipalities analyzed were efficient in allocating spending in the education function.

KEYWORDs: Public Expenditures. Education. Efficiency. Socioeconomic Development. 


\section{INTRODUÇÃO}

Dentre as obrigações do Governo, a educação é considerada um dos pilares para que haja desenvolvimento econômico sustentável. Uma sociedade com maior nível de escolaridade tende a ser mais consciente politicamente, menos desigual socialmente e mais produtiva economicamente, o que poder ser averiguado pelo modelo de crescimento endógeno de Paul Romer (1990), no qual, a taxa de crescimento da renda per capta depende fundamentalmente do estoque de capital humano existente na economia. Essa variável, no modelo do autor, mensura o efeito cumulativo de atividades como a educação formal e o treinamento no trabalho sobre a produtividade dos trabalhadores.

Para se conquistar bons índices na educação de uma nação, o ponto de partida é a qualidade da educação por meio de: professores capacitados e interessados em se especializar, materiais de qualidade e estruturas físicas adequadas. Com isso, os resultados esperados com esses investimentos terão uma maior chance de êxito, pois o ensino básico é o período decisivo para a formação escolar e também social dos alunos.

A Constituição da República Federativa do Brasil de 1988 afirma, em seu artigo $6^{\circ}$, que a educação é um direito social, o primeiro a ser citado na ordem dos direitos sociais que estabelecem a igualdade entre os brasileiros, e também no artigo 205으, que a educação é um direito de todos e dever do Estado e da família, a qual será promovida e incentivada com a colaboração da sociedade, visando ao pleno desenvolvimento da pessoa, seu preparo para o exercício da cidadania e sua qualificação para o trabalho.

A definição do montante de recursos necessários para atingir um determinado desempenho educacional é denominado na literatura como "adequação" do financiamento. Esse conceito é utilizado na definição de políticas públicas para garantir um investimento mínimo em educação (HANUSHEK, 1994; RUGGIERO, 2007). No Brasil, a Lei $n^{\circ} 9.394$ de 1996, estabelece que os Estados e os municípios devem destinar, no mínimo, $25 \%$ da receita orçamentária para a manutenção e o desenvolvimento do ensino público. Além disso, a Meta 20 do Plano Nacional de Educação, Lei n 13.005/2014, visa a ampliar o investimento público em educação de forma a atingir, no mínimo, o equivalente a 10\% do PIB até 2024. Porém, é necessário também garantir que os recursos destinados à educação sejam devidamente alocados para gerar qualidade nos resultados obtidos pelos alunos, uma vez que vários estudos identificaram que existe ineficiência na alocação dos gastos em educação (GUPTA E VERHOEVEN, 2001; CLEMENTS, 2002, AFONSO E AUBYN, 2005; AFONSO E AUBYN, 2006; GONÇALVES AND FRANÇA, 2013; CARVALHO AND SOUSA, 2014; OLIVEIRA ET AL. 2018).

O Rio Grande do Sul, no ano de 2012, foi o Estado brasileiro que menos investiu em educação em comparação ao que arrecadou, confor- 
me indicou um levantamento do Fundo Nacional de Desenvolvimento da Educação (FNDE). Além disso, no ano de 2016, o Estado teve o pior desempenho no Índice de Desenvolvimento da Educação Básica (IDEB) desde que a avaliação começou a ser feita em 2005.

Diante disso, o estudo pretende analisar a eficiência dos gastos públicos com educação no Rio Grande do Sul em 2015, através do cálculo do indicador de eficiência dos gastos com educação, construído a partir do Índice de Desenvolvimento da Educação Básica (IDEB) e de um indicador de despesa, que considera os gastos totais com educação pública e o número de estudantes matriculados.

\section{REVISÃO DA LITERATURA}

\subsection{EFICIÊNCIA DOS GASTOS PÚBLICOS}

A eficiência não se preocupa com os fins, mas simplesmente com os meios. $\mathrm{O}$ alcance dos objetivos visados não entra na esfera de competência da eficiência, é um assunto ligado à eficácia. Nem sempre a eficiência e a eficácia são similares, uma empresa pode ser eficiente em suas operações e pode ser não eficaz, ou vice-versa. Então a eficiência refere-se aos meios, enquanto a eficácia está relacionada com os resultados. (CHIAVENATO, 1993).

A eficiência técnica, então, é um critério que permite comparar o desempenho de unidades de produção pertencentes a ambientes institucionais diferentes. As instituições públicas perseguem objetivos diferentes aos de uma instituição privada cuja busca essencial é o lucro. Portanto, o campo da eficiência técnica é um campo comum para se estabelecer comparações entre instituições de diferentes naturezas, (LOVELL e SCHIMIDT, 1993).

Um bom planejador social utiliza os recursos públicos municipais, arrecadados através de impostos ou transferências federais e estaduais, para maximizar a melhoria da qualidade de vida dos munícipes sendo em educação básica, saúde, segurança e outros serviços. Os municípios não são igualmente eficientes, pois a gestão municipal pode ser afetada por diversos fatores, sejam eles conselhos setoriais, auditores institucionais externos e pela disputa eleitoral de cargo (MOTTA E MOREIRA, 2007).

Conforme Filho (2009, p.204):

Existe claramente um problema de gestão na educação pública. Muitas escolas chegam a meados de abril sem professores alocados para todas as turmas, pois muitas vezes o professor inicialmente alocado pediu transferência para outra escola. Se não existe professor lecionando a matéria, os alunos não irão aprender. Além disso, não há estímulo para que os professores compareçam a todas as aulas. Como os salários e a progressão na carreira não dependem do seu desempenho, a tendência natural da maioria dos professores da rede pública é a acomodação. Cabe ressaltar que existe uma parcela significativa dos 
professores que se dedica firmemente ao ensino na rede pública, mas, infelizmente, os resultados indicam que esta parcela não está sendo suficiente para melhorar o aprendizado dos alunos.

Para Silva, Souza e Araújo (2013), é considerado mais eficiente quem é responsável pela maior produção de certos produtos a um determinado custo ou quem diminui o custo de produzir certa quantidade de produtos, considerando o tempo decorrido e qualidade destes produtos. Neste contexto, os autores afirmam que a realização da avaliação da eficiência na esfera pública se torna necessária devendo ser adotada pelos gestores públicos uma vez que o reflexo dos investimentos realizados nos diversos setores deve ser transformado em serviços de qualidade e na melhoria dos indicadores sociais da população. Diante do dilema econômico contemporâneo, onde os recursos são escassos e as necessidades da sociedade se apresentam de forma abundante, a análise da qualidade dos gastos públicos é fundamental.

Para Brunet, Bertê e Borges (2008), para que os gastos públicos com educação sejam eficazes, é necessário que o aumento dos gastos seja acompanhado de mais critério e qualidade, visto que melhoras na educação demandam investimentos de longo prazo. E mais, os gastos com educação devem proporcionar a eficiência e a igualdade nos sistemas de ensino, a fim de que o desempenho e o desenvolvimento dos alunos possam se concretizar.

Para o Tribunal de Contas da União - TCU (Manual de Auditoria Operacional-2010) o conceito de eficiência na avaliação de políticas públicas envolve mais de uma variável e apresenta a seguinte definição:

"A eficiência é definida como a relação entre os produtos (bens e serviços) gerados por uma atividade e os custos dos insumos empregados para produzi-los, em um determinado período de tempo, mantidos os padrões de qualidade. Essa dimensão refere-se ao esforço do processo de transformação de insumos em produtos. Pode ser examinada sob duas perspectivas: minimização do custo total ou dos meios necessários para obter a mesma quantidade e qualidade de produto; ou otimização da combinação de insumos para maximizar o produto quando o gasto total está previamente fixado. Nesse caso, a análise do tempo necessário para execução das tarefas é uma variável a ser considerada. A eficiência pode ser medida calculando-se e comparando-se o custo unitário da produção de um bem ou serviço."

O conceito de "qualidade do gasto público" ainda é um pouco impreciso, envolvendo a ação em todos os setores os públicos, mas certamente está associado à atuação mais eficiente e eficaz do governo. A administração do setor público brasileiro ainda está longe dos conceitos que levaram às reformar dos países desenvolvidos, sendo que os conceitos discutidos na atualidade ainda não foram absorvidos 
de modo a redundar em leis e projetos que alterassem a estrutura da gestão administrativa, mantendo a ênfase nos processos administrativos, e não nos resultados para a população (BRUNET; BERTÉ; BORGES, 2012).

\subsection{EDUCAÇÃO E DESENVOLVIMENTO}

A educação pode ser entendida como uma prática social, uma atividade humana e histórica que se define no conjunto das relações sociais, tendo como função produzir em cada indivíduo singular, a humanidade que é produzida historicamente e coletivamente pelo conjunto dos homens (SAVIANI, 2000; FRIGOTTO, 2010). Assim, não há dúvida que o ensino básico universal de qualidade seja uma exigência moral das sociedades modernas, possibilita uma maior equidade social, preserva os valores culturais e garante uma melhor funcionalidade econômica (SOARES, 2005). Porém, Libâneo (2012) alerta para o agravamento da dualidade da escola pública brasileira atual, caracterizada como uma escola do conhecimento para os ricos e como uma escola do acolhimento social para os pobres, que contribui para reproduzir e manter desigualdades sociais.

Qualquer política educacional, verdadeiramente igualitária, terá que dar ênfase aos primeiros anos de escolaridade e, mais do que isso, tentar educar a criança antes que ela chegue à escola primária. Estamos cada vez mais convencidos de que, jardim de infância, escola maternal e maior número de horas de permanência na escola primária são as variáveis cruciais em qualquer plano educacional ambicioso, já que, apenas nos primeiros anos de vida, é ainda possível e economicamente viável influenciar o desenvolvimento cognitivo e da personalidade. (CASTRO, 1976).

A educação é um dos principais mecanismos para tirar permanentemente as pessoas de uma situação de pobreza e possibilitar seu acesso ao mercado de trabalho. Além disto, ao melhorar o nível educacional de sua população, os países conseguem reduzir sua desigualdade de renda, aumentar a adoção de novas tecnologias e com isto crescer de forma sustentada no longo prazo. Assim, não restam dúvidas de que a educação é uma das variáveis mais importantes, senão a mais importante, para aumentar o bem-estar de uma sociedade. (FILHO, 2009).

O conhecimento é a matéria-prima mais importante de que uma pessoa necessita para realizar os trabalhos diários, é a maior força de valor econômico. Aqueles que não são trabalhadores do conhecimento não são bem remunerados. Informação e conhecimento são tanto matéria-prima quanto o produto de trabalho. (STEWART, 1998).

Investimentos na qualidade da população são um dos meios mais importantes para aumentar a produtividade da força de trabalho. Investimentos no ensino escolar são muito mais do que atividade de consumo, satisfação ou utilidade durante a frequência escolar, são uma forma de proporcionar futuros serviços. Esses futuros serviços podem 
se transformar em maiores rendas, capacidade de auto emprego e maiores opções de consumo. Existem também estudos que mostram que a capacidade empreendedora é aumentada por um ensino escolar adicional (SCHULTZ, 1964).

Barros e Mendonça (1997) avaliaram os impactos de uma expansão quantitativa educacional sobre o desenvolvimento socioeconômico futuro, e constataram que um aumento de investimentos em educação leva a um crescimento da renda per capita, o que por sua vez leva a uma redução da taxa de mortalidade e um aumento na expectativa de vida. Observaram também que aumentos em investimentos educacionais reduzem o crescimento populacional e elevam os indicadores de desempenho escolar.

\subsection{TEORIA DO CAPITAL HUMANO}

Segundo Schultz (1971), A partir da década de 60, a Teoria do Capital Humano buscava mostrar que os países em desenvolvimento, como o Japão, que foram destruídos na Segunda Guerra Mundial, conseguiram reconstruir suas economias em tão pouco tempo, em explicação dessa teoria. $\mathrm{O}$ autor cita alguns países que alcançaram um grande crescimento econômico devido a esses pressupostos. Desse período em diante passou a figurar a defesa de que o investimento na capacidade humana pode implicar no desenvolvimento na área econômica e no campo competitivo de diversos países.

O investimento no "fator humano" passa a significar um dos determinantes básicos para o aumento da produtividade e elemento de superação do atraso econômico. Do ponto de vista macroeconômico, constitui-se no fator explicativo das diferenças individuais de produtividade e de renda e, consequentemente, de mobilidade social (FRIGOTTO, 1999).

O capital humano é fonte de inovação e renovação, seja em laboratórios, universidades ou em empresas. Ele é formado e empregado quando uma parte maior do tempo e do talento dos trabalhadores é dedicado às atividades que resultam em inovação. Para as empresas a preocupação é como adquirir volume suficiente de capital humano que possa gerar lucro. "O dinheiro tem poder, mas não pensa; as máquinas operam, muitas vezes melhor do que qualquer ser humano, mas não inventam" (STEWART, 1998).

Considerando que o capital humano tem como base desenvolver habilidades, conhecimentos e competências e está diretamente relacionado a melhores condições de desenvolvimento econômico, então para que ocorra essa melhoria, é necessário investir em educação, habitação, segurança, transporte, moradia, pois quanto menor o investimento em capital humano, menor será a competitividade do povo.

Para Schultz (1964, p.37)

Sempre que a instrução elevar as futuras rendas dos estudantes, teremos um investimento. É um investimento no capital humano, sob a forma de habilidades 
adquiridas na escola. Existem numerosos investimentos no capital humano e as cifras tornam-se elevadas. Pode-se dizer, na verdade, que a capacidade produtiva do trabalho é, predominantemente, um meio de produção produzido. Nós "produzimos", assim, a nós mesmos e, neste sentido, os "recursos humanos" são uma consequência de investimentos entre os quais a instrução é da maior importância.

De acordo com Schultz (1987), o capital humano contribui para o aumento da produtividade do trabalho e na capacidade empreendedora das pessoas tanto nas atividades ligadas a agricultura, industriais e produção doméstica. Tal capacidade proporciona melhores oportunidades de emprego levando a um maior consumo atual e futuro. O ensino escolar é um investimento e todas as despesas educacionais devem ser tratadas como tal, e não como um gasto de consumo. Quanto mais uma pessoa investir na sua formação escolar, na constituição de seu capital pessoal, mais valor de mercado terá, garantindo rendimentos superiores futuramente, ascendendo socialmente e economicamente. Dessa forma, um maior investimento em capital humano traz enormes benefícios para a economia.

\section{METODOLOGIA}

\subsection{COLETA DE DADOS}

Para a construção e operacionalização do referido artigo foram utilizados dados secundários de órgãos de pesquisa referentes ao ano de 2015 para os municípios do Rio Grande do Sul, sendo extraídos da base de dados do Instituto Nacional de Estudos e Pesquisas Educacionais Anísio Teixeira (INEP), Fundação de Economia e Estatística (FEE) e Secretaria do Tesouro Nacional do Ministério da Fazenda (STN).

Os dados referentes número de docentes, escolas e matrículas foram extraídos do FEE. Para verificar o desempenho das escolas dos municípios do Rio Grande do Sul, foi utilizado o Índice de Desenvolvimento da Educação Básica (IDEB), que foi criado em 2007 e reúne, em um só indicador, os resultados de dois conceitos igualmente importantes para a qualidade da educação: o fluxo escolar e as médias de desempenho nas avaliações. Ele é calculado a partir dos dados sobre aprovação escolar, obtidos no Censo Escolar, e das médias de desempenho nas avaliações do Inep, o Sistema de Avaliação da Educação Básica (Saeb) - para as unidades da federação e para o país, e a Prova Brasil - para os municípios.

O índice varia de zero a dez e a combinação entre fluxo e aprendizagem tem o mérito de equilibrar as duas dimensões: se um sistema de ensino retiver seus alunos para obter resultados de melhor qualidade no Saeb ou Prova Brasil, o fator fluxo será alterado, indicando a necessidade de melhoria do sistema. Se, ao contrário, o sistema apressar a aprovação do aluno sem qualidade, o resultado das avaliações indicará igualmente a necessidade de melhoria do sistema. O IDEB também 
é importante por ser condutor de política pública em prol da qualidade da educação. É a ferramenta para acompanhamento das metas de qualidade do Plano de Desenvolvimento da Educação (PDE) para a educação básica.

\subsection{EFICIÊNCIA DOS GASTOS PÚBLICOS COM EDUCAÇÃO}

Para avaliar a eficiência dos gastos públicos com educação nos municípios do Rio Grande do Sul, foram selecionadas as seguintes variáveis:

a) Despesas municipais com educação.

b) Matrículas nas redes municipais do ensino básico.

As duas variáveis permitem calcular a despesa por aluno matriculado e compõem o indicador de despesa do ensino básico público das redes municipais e estaduais. É importante observar que esse indicador representa a média da despesa realizada por estudante matriculado nos municípios do Rio Grande do Sul.

Para o cálculo do desempenho escolar dos estudantes, utilizam-se:

a) Escores obtidos pelos estudantes na avaliação do IDEB na rede pública, que engloba as redes: federal, estadual e municipal, do $5^{\circ}$ ano do ensino fundamental.

b) Escores obtidos pelos estudantes na avaliação do IDEB na rede pública, que engloba as redes: federal, estadual e municipal, do $9^{\circ}$ ano do ensino fundamental.

Conforme Brunet, Bertê e Borges (2008) a composição dessas variáveis define o indicador de desempenho dos estudantes do ensino básico público das redes municipais e estaduais do Rio Grande do Sul do $5^{\circ} \mathrm{e}$ $9^{\circ}$ ano do ensino fundamental. Com esses indicadores, é possível calcular a eficiência dos gastos públicos com educação através de:

Indicador de desempenho dos estudantes

$$
\text { Indicador de despesa na função Educação }
$$

E é o indicador de eficiência dos gastos públicos na função educação para os municípios. Os indicadores de desempenho dos estudantes e de despesa na função educação devem se referir ao mesmo ano.

O resultado da razão entre os indicadores de desempenho dos estudantes e o indicador de despesa na função educação permite a classificação dos municípios, analisando o desempenho de cada município em particular para poder comparar aos resultado obtidos pelos demais.

Para a obtenção do resultado final, relativo, faz-se uso do tratamento estatístico denominado escore padronizado pelo método da função distribuição acumulada normal. 
Assim, o desempenho dos estudantes para determinada variável em definido município, é expresso na seguinte função:

$$
D=f\left[(\partial-\mu d) \sigma d^{-1}\right]
$$

Onde:

$D$ é o indicador de desempenho dos estudantes e $f$ é a função Distribuição Acumulada Normal. d é o escore bruto da variável de desempenho selecionada para determinado município. E $\mu d$ e бd são, respectivamente, a média e o desvio-padrão dos escores brutos da variável de desempenho de todos os municípios do Estado.

O valor do indicador de desempenho, $D$, para cada município, varia no intervalo de 0 a 1 . Quanto mais próximo do valor unitário, melhor é o desempenho dos estudantes daquele município.

De forma análoga ao indicador de desempenho, para o cálculo do indicador de despesa na função educação, tem-se:

$$
G=f\left\{\left[\left(s m^{-1}\right)-\mu \mathrm{g}\right] \sigma \mathrm{g}^{-1}\right\}
$$

Onde:

G é o indicador de despesa na função educação de cada município; s é a despesa total na função educação do ensino básico público das redes municipais e estaduais; $m$ é o total de matrículas na rede pública do ensino básico. E $\mu g$ e бg são, respectivamente, a média e o desviopadrão da despesa por aluno de todos os municípios do Estado.

O indicador de despesa, $G$, a exemplo do indicador de desempenho, varia no intervalo de 0 (menor despesa realizada) a 1 (maior despesa realizada).

Portanto, o indicador de eficiência dos gastos públicos em educação, E, é dado por:

$$
E=f\left[(\partial-\mu \mathrm{d}) \sigma \mathrm{d}^{-1}\right] / f\left\{\left[\left(s m^{-1}\right)-\mu \mathrm{g}\right] \sigma \mathrm{g}^{-1}\right\}
$$

Basicamente, o indicador de eficiência dos gastos públicos da função educação informa, comparativamente, o quanto é retornado em termos de desempenho escolar dos estudantes de determinado município por unidade de despesa realizada pela administração direta daquela unidade.

Por sua metodologia de construção, baseada em escores padronizados, tanto para a despesa, quanto para o desempenho, pode-se afirmar que o valor mínimo esperado do indicador de eficiência dos gastos para qualquer município é um $(1,00)$. Dessa forma, surge o conceito de fronteira de desempenho mínimo: Municípios com valor do indicador de eficiência inferior a um $(1,00)$ são considerados ineficazes, ao passo que as unidades com indicador de qualidade igual ou superior a um $(1,00)$ são consideradas eficazes.

As principais vantagens da utilização do indicador de eficiência dos gastos públicos na educação são a facilidade de construção 
e a interpretação dos resultados obtidos pela simples comparação: Municípios com indicador de eficiência dos gastos mais elevado obtêm maior retorno na utilização dos recursos públicos, ou seja, a qualidade do seu gasto é melhor.

\section{ANÁLISE DOS RESULTADOS}

Em 2015, o IDEB do Rio Grande do Sul foi 5,5 para o $5^{\circ}$ ano e 4,2 para o $9^{\circ}$ ano do ensino fundamental. A Tabela 1 apresenta a distribuição dos 496 municípios do Rio Grande do Sul nas categorias de eficiência dos gastos públicos em educação. Os municípios que obtiveram índice de eficiência inferior a um foram considerados ineficientes. Municípios com valor superior a um, são considerados eficientes e os que têm o valor do índice maior que a soma da média e do desvio padrão do ano observado são classificados como altamente eficientes.

É possível observar que a maioria dos municípios são eficientes ou altamente eficientes no que se refere aos gastos públicos com educação ( $47 \%$ no $5^{\circ}$ ano e $41 \%$ no $9^{\circ}$ ano). Mesmo assim, ainda existem muitos municípios no estado que são considerados ineficientes na alocação dos gastos (29\% no $5^{\circ}$ ano e $23 \%$ no $9^{\circ}$ ano). Assim, os resultados estão de acordo com a literatura que aponta que nem sempre o aumento no montante dos recursos garante melhora proporcional no desempenho dos estudantes do ensino básico, uma vez que existem evidências de ineficiência na alocação dos gastos em educação por parte de municípios e escolas (GONÇALVES e FRANÇA, 2013; CARVALHO e SOUSA, 2014; OLIVEIRA ET AL. 2018).

Além disso, o Rio Grande do Sul, que sempre foi referência nos resultados da educação, vem perdendo a posição de destaque comparativamente a alguns dos demais Estados do Brasil, como o Ceará, por exemplo (INEP, 2017). O Estado gaúcho passa por crise fiscal, ocasionada pelo agravamento da dívida junto à União e os repetidos déficits ao longo dos anos. A partir de 2015, uma das medidas adotadas pelo governo foi a divisão em parcelas dos salários dos funcionários do executivo ao longo do mês, ocasionando vários períodos de greve dos professores e rotatividade do corpo docente (FRIO E FRANÇA, 2019). Em 2017, diversos municípios também começaram a parcelar os salários de seus servidores. Brunet et al. (2008) destacam que as mudanças relevantes, em termos de qualidade da Educação, não são detectáveis em curtos períodos de tempo e, dessa forma, é possível que os resultados desse estudo não tenham captado a deterioração da qualidade da educação pública no Estado nos anos mais recentes. Assim, para continuar ou passar a ser eficaz, o aumento do gasto precisa vir acompanhado de mais critério e qualidade a alocação dos gastos, além de garantir que investimentos a longo prazo (BRUNET et al. 2008). 


\section{Revista de Gestão Pública}

PRATICAS E DESAFIOS

ISSN: 2177-1243

TABELA 1 - Classificação dos municípios quanto a eficiência dos gastos públicos com educação

\begin{tabular}{lcccc}
\hline & Não Observados & Ineficientes & Eficientes & Altamente Eficientes \\
\hline $5^{\circ}$ ano & $119(24 \%)$ & $145(29 \%)$ & $181(37 \%)$ & $51(10 \%)$ \\
$9^{\circ}$ ano & $177(36 \%)$ & $112(23 \%)$ & $149(30 \%)$ & $58(11 \%)$ \\
\hline
\end{tabular}

FONTES: FEE Dados e Secretaria do Tesouro Nacional do Ministério da Fazenda.

A Figura 1 apresenta mapas temáticos do índice de eficiência dos gastos públicos com educação dos municípios do Rio Grande do Sul do $5^{\circ}$ e $9^{\circ}$ ano do ensino fundamental. Devido à falta de notas do IDEB, muitos índices de eficiência do gasto público com educação não foram observados, sendo representados na cor branca nos mapas. Os números em colchetes representam a quantidade de municípios em cada classe observada. Os municípios com maior índice de eficiência localizam-se na região Norte do Estado, que concentra os municípios com maior Ideb e caracteriza-se pelo maior dinamismo econômico e melhores indicadores de desenvolvimento.

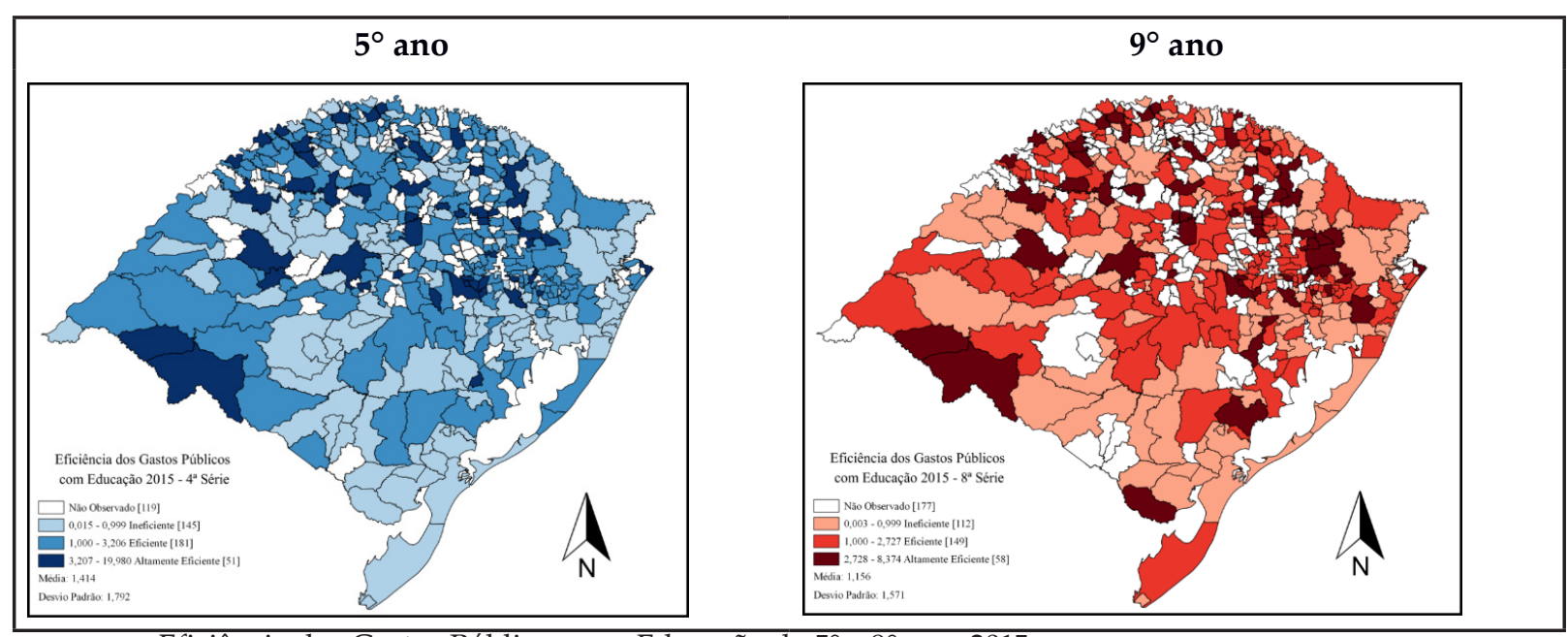

FIGURA 1 - Eficiência dos Gastos Públicos com Educação do $5^{\circ}$ e $9^{\circ}$ ano, 2015

FONTES: FEE Dados e Secretaria do Tesouro Nacional do Ministério da Fazenda 
Devido ao demasiado número de municípios do Rio Grande do Sul, seria inviável demonstrar os valores de todos os municípios no período analisado. Para simplificar a visualização, realizou-se um ranking do índice de eficiência dos gastos públicos com educação, com seus respectivos valores, dos vinte melhores e piores municípios do $5^{\circ}$ e $9^{\circ}$ ano do ensino fundamental no ano de 2015, conforme o Quadro 1.

QUADRO 1 - Ranking dos 20 municípios com maior (+) e menor (-) indicador de eficiência dos gastos públicos em educação do $5^{\circ}$ e $9^{\circ}$ ano do ensino fundamental

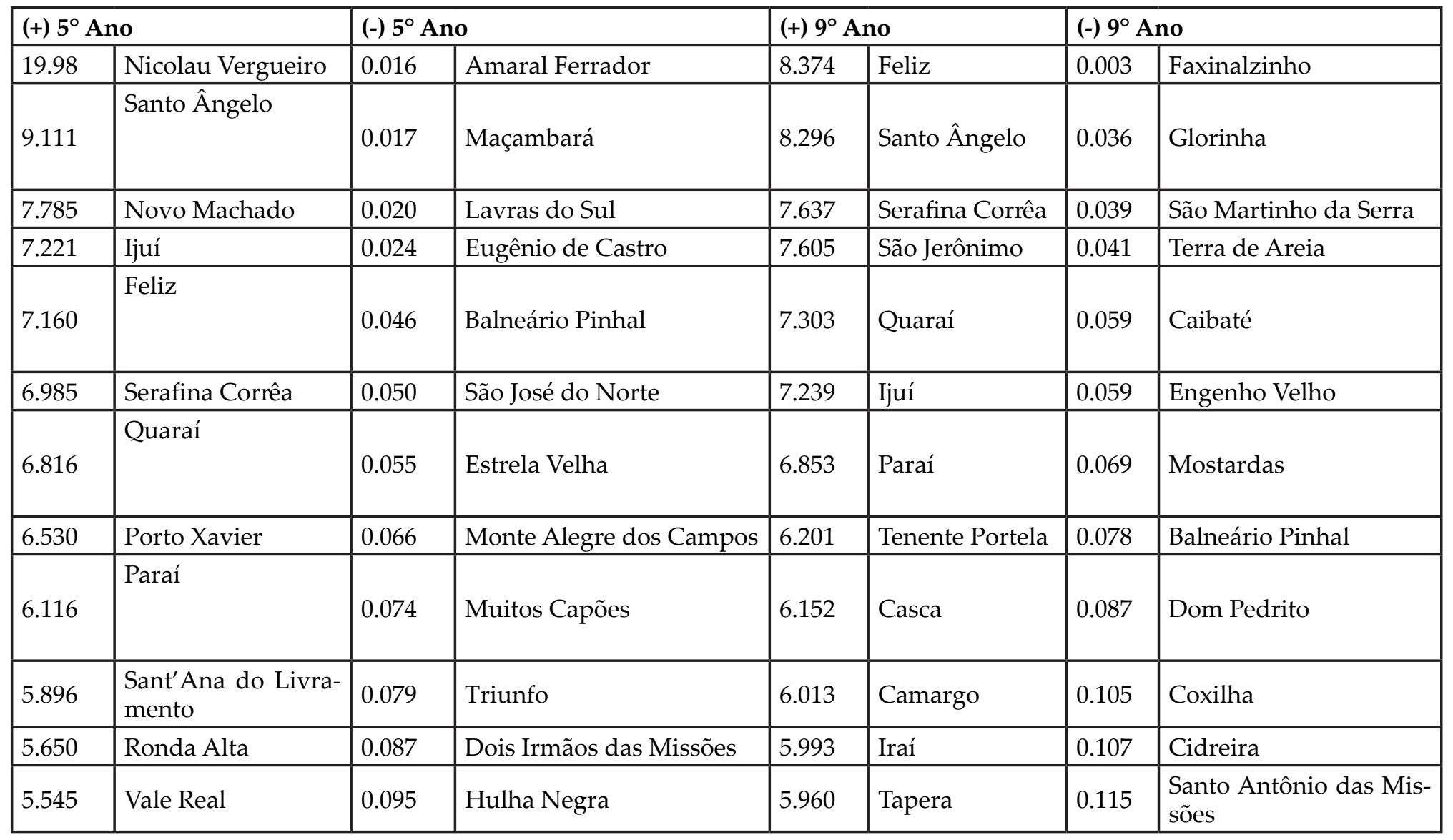




\begin{tabular}{|l|l|l|l|l|l|l|l|}
\hline 5.545 & Júlio de Castilhos & 0.104 & Faxinalzinho & 5.747 & Porto Xavier & 0.120 & São José do Norte \\
\hline 5.493 & Santiago & 0.129 & Coronel Bicaco & 5.287 & Espumoso & 0.120 & General Câmara \\
\hline 5.485 & Tapera & 0.134 & Dom Feliciano & 5.166 & $\begin{array}{l}\text { Júlio de Casti- } \\
\text { lhos }\end{array}$ & 0.145 & $\begin{array}{l}\text { Monte Alegre dos Cam- } \\
\text { pos }\end{array}$ \\
\hline 5.475 & São Luiz Gonzaga & 0.154 & Eldorado do Sul & 5.095 & Venâncio Aires & 0.171 & Gramado Xavier \\
\hline 5.468 & Venâncio Aires & 0.160 & Brochier & 5.057 & Ronda Alta & 0.175 & Chuí \\
\hline 5.338 & Bom Retiro do Sul & 0.162 & Cidreira & 5.050 & Panambi & 0.182 & Tavares \\
\hline 5.243 & São Marcos & 0.165 & Santa Margarida do Sul & 4.974 & Jaguarão & 0.201 & Morro Redondo \\
\hline 5.145 & Casca & 0.170 & Turuçu & 4.763 & Independência & 0.213 & Triunfo \\
\hline
\end{tabular}

FONTES: FEE Dados e Secretaria do Tesouro Nacional do Ministério da Fazenda.

\section{CONSIDERAÇÕES FINAIS}

A educação deve ser um dos principais investimentos do Estado, pois promove a cidadania, justiça social, contribui para uma maior produtividade, afeta o nível de bem-estar da população, ou seja, gera uma série de benefícios para a sociedade e garante um desenvolvimento. Dessa forma o objetivo do estudo foi avaliar a eficiência dos gastos públicos com educação no ensino fundamental, para isso foi calculado os índices de eficiência do gasto público com educação dos municípios, representados através de tabelas de ranking e mapas temáticos do Rio Grande do Sul.

Os resultados indicaram que mais da metade dos municípios analisados do Rio Grande do Sul se mostraram eficientes na alocação dos recursos em 2015. Dos 496 municípios avaliados, no $5^{\circ}$ ano do ensino fundamental, 47\% dos municípios foram considerados eficientes nos gastos públicos com educação e $41 \%$ no $9^{\circ}$ ano. 


\section{REFERÊNCIAS BIBLIOGRÁFICAS}

ABRAHÃO, Jorge; MOSTAFA, Joana; HERCULANO, Pedro. Gastos com a Política Social: alavanca para o crescimento com distribuição de renda. IPEA comunidade nำ5, fevereiro de 2011.

AFONSO, A. \& AUBYN, M. S. (2005). Non-parametric approaches to education and health efficiency in OECD countries, Journal of Applied Economics 8(2), 227-246.

AFONSO, A. AND ST AUBYN, M. (2006). Crosscountry efficiency of secondary education provision: a semiparametric analysis with non-discretionary inputs. Economic Modelling. 23, 476-91.

BARROS, R. P. de; MENDONÇA, R. Investimentos em Educação e Desenvolvimento Econômico. Texto para discussão no 525. IPEA - Rio de Janeiro, novembro de 1997.

BRASIL. Constituição (1988). Constituição da República Federativa do Brasil. Brasília, DF: Senado, 1988.

BRESSER-PEREIRA, L. C. (2006). O conceito histórico de desenvolvimento econômico. Texto para Discussão da Escola de Economia de São Paulo da Fundação Getúlio Vargas - EESP/FGV n 157, dezembro 2006.

BRUNET, Júlio Francisco Gregory; BERTÊ, Ana Maria de Aveline; BORGES, Clayton Brito. Qualidade do Gasto Público em Educação nas Redes Públicas Estaduais e Municipais. Finanças Públicas. XIII Prêmio Tesouro Nacional, 2008.

BRUNET, Júlio Gregory; BERTÉ, Ana Mariana de Aveline; BORGES, Claynton Brito. O Gasto Público no Brasil: Entenda a qualidade do gasto público nos estados brasileiros. Rio de Janeiro: Elsevier, 2012.

CARVALHO, L. D. B. D.; SOUSA, M. D. C. S. D. (2014). Eficiência das escolas públicas urbanas das regiões Nordeste e Sudeste do Brasil: uma abordagem em três estágios. Estudos Econômicos (São Paulo) 44(4), 649-684.

CASTRO, Cláudio de Moura. Desenvolvimento Econômico, Educação e Educabilidades. 2aed. Rio de Janeiro, 1976.

CLEMENTS, B. (2002). How efficient is education spending in Europe? European Review of Economics and Finance 1(1), 3-26.

CHIAVENATO, Idalberto. Introdução à Teoria Geral da Administração. 4⿳⺈冂a ed. São Paulo, McGraw Hill, 1993, p.238.

EDVINSSON, Leif; MALONE, Michel. Capital intelectual: 
descobrindo o valor real de sua empresa pela identificação de seus valores internos. São Paulo: Makron Books, 1998.

FEE - Fundação de Economia e Estatística. Disponível em: <http://www.fee.rs.gov.br/> Acesso em: abr. 2017.

FOCHEZATTO, Adelar. VALENTINI, Paulo J. Economias de Aglomeração e Crescimento Econômico Regional: Um Estudo Aplicado ao Rio Grande do Sul Usando um Modelo Econométrico com Dados de Painel. Revista EconomiA, Brasília (DF), v.11, n.4, p.243-266, Dezembro 2010.

FRIGOTTO, G. (1999). A produtividade da escola improdutiva. Um (re) exame das relações entre educação e estrutura econômico-social capitalista. 5ํeed. São Paulo: Cortez, 1999.

FRIGOTTO, G. (2000). Educação e a crise do capitalismo real. São Paulo: Cortez, 2010.

FRIO, G. S.; FRANÇA, M. T. A. (2019). Efeito do Parcelamento de Salários sobre o Indicador de Regularidade Docente: Uma análise para o Rio Grande do Sul. Anais do XXII Encontro de Economia da Região Sul, 2019.

GONÇALVES, F. D. O;; FRANÇA, M. T. A. (2013). Eficiência na provisão de educação pública municipal: uma análise em três estágios dos municípios brasileiros. Estudos Econômicos 43(2), 271-299.

GUPTA, S.; VERHOEVEN, M. (2001). The efficiency of government expenditure: experiences from Africa, Journal of Policy Modeling 23(4), 433-467.

HANUSHEK, E. A. (1994). Jaundiced View of "Adequacy" in School Finance Reform. Educational Policy 1994 8: 460

INEP (2017). Nota Técnica: Resultados do Índice de Desenvolvimento da Educação Básica (Ideb). Brasília: Instituto Nacional de Estudos e Pesquisas Educacionais Anísio Teixeira, 2017.

LIBÂNEO, J. C. (2012). O dualismo perverso na escola pública brasileira: escola do conhecimento para os ricos, escola do acolhimento social para os pobres. Educação e Pesquisa, São Paulo, vol. 38, n. 1, p. 13-28, 2012

LOVELL, C.A.K.; SCHMIDT, S.S. The measurement of productive efficiency. New York, Oxford University, 1993.

MENEZES, Naercio A. F. Sociedade e Economia: Estratégias de Crescimento e Desenvolvimento. Brasília: 
2009 (Livro no 13, capítulo 20). Disponível em: <http:// www.ipea.gov.br/portal/images/stories/PDFs/livros/ livro_sociedadeeeconomia.pdf $>$. Acesso em mar. 2017.

MOTTA, Ronaldo S. da; MOREIRA, Ajax. Eficiência na gestão municipal no Brasil. IPEA, Rio de Janeiro, set. 2007, (Texto para discussão $n^{-}$1301). Disponível em: <http://www.ipea.gov.br/portal/images/stories/ PDFs/TDs/td_1301.pdf $>$. Acesso em: jun. 2017

OLIVEIRA, V. R.; SOUZA, W. P. S. F.; ANNEGUES, A. C. (2018). Eficiência e autonomia escolar: evidências para o período 2007-2013. Economia Aplicada, v. 22, n. 2, 2018, pp. 5-46

ROMER, P. M. Endogenous Technological change. The journal of Political Economy, The university of Chicago Press, v. 98, 1990.

ROSA, Mariana Santos da. Análise dos gastos públicos com educação em Santa Catarina: 2002 - 2012. Monografia Defendida - Curso de Ciências Econômicas, Universidade Federal de Santa Catarina, Florianópolis, 2014.

RUGGIERO, J (2007). Measuring the Cost of Meeting Minimum Educational Standards: An Application of Data Envelopment Analysis, Education Economics, 15:1, 1-13, DOI: 10.1080/09645290601133845

SAVIANI, D. (2000) Pedagogia histórico-crítica: primeiras aproximações. Campinas: Autores Associados, 2000.

SCHULTZ, Theodore W. O Capital Humano: Investimentos em Educação e Pesquisa. Zahar Editores, Rio de Janeiro, 1971.

SCHULTZ, Theodore W. O Valor Econômico da Educação. Zahar Editores, Rio de Janeiro, 1964.

SCHULTZ, Theodoro W. Investindo no Povo. Tradução Élcio Gomes de Cerqueira. Rio de Janeiro: Forense Universitária, 1987.

SILVA, Maurício Corrêa da; SOUZA, Fábia Jaiany Viana de; ARAÚJO, Aneide Oliveira. Análise da eficiência dos gastos públicos com educação nas capitais brasileiras. Contexto, Porto Alegre, v. 13, n. 24, p.7-21, maio 2013.

SOARES, José F. Qualidade e equidade na educação básica brasileira: fatos e possibilidades. In: BROCK, Colin e SCHWARTZMAN, Simon (org); Os desafios da educação no Brasil. Tradução de Ricardo Silveira. Rio de Janeiro: Nova Fronteira, p. 91-117, 2005.

SOLOW, R. M. Technical Change and the Aggregate 
Production Function. Review of Economics and Statistics. MIT Press, v. 39, 1957.

STEWART, Thomas A. Capital Intelectual. 15 reimpressão. Rio de Janeiro: Elsevier, 1998.

TCE - Tribunal de Contas do Estado do Rio Grande do Sul. Disponível em: <http://www1.tce.rs.gov.br/portal/page/portal/ tcers/consultas/indicadores/educacao $>$. Acesso em: abr. 2017. 